\title{
Efeito do extrato aquoso de Scutia buxifolia sobre conteúdo sérico de albumina e peso corporal de ratos
}

\author{
Robson Borba de Freitas ${ }^{1}$, Roberta da Silva Jesus ${ }^{2}$, Isabel Cristina da Costa Araldi ${ }^{3}$, \\ Bruno Tomazele Rovan², Thiele Faccim de Brum², Mariana Piana1', Aline Augusti Boligon², \\ Glauce Regina Pigatto ${ }^{4}$, Gilberti Helena Hübscher Lopes ${ }^{5}$, \\ Margareth Linde Athayde ${ }^{2}$, Liliane de Freitas Bauermann ${ }^{2}$
}

\begin{abstract}
RESUMO
Scutia buxifolia é uma planta usada no tratamento de doenças cardíacas. No entanto, seus efeitos tóxicos no fígado são pouco conhecidos. Ratos Wistar ( $\mathrm{n}=32$ ) foram divididos em 4 grupos: controle e os tratados com 100, 200 e $400 \mathrm{mg}$ do extrato aquoso liofilizado de S. buxifolia (EASB) / kg de peso corporal diariamente, durante 30 dias. O sangue dos animais foi coletado no $15^{\circ}$ e $30^{\circ}$ dia de experimento para a realização da dosagem de albumina sérica. As amostras foram centrifugadas a $3000 \mathrm{rpm}$ durante 15 minutos. Este estudo teve por objetivo investigar os efeitos hepatotóxicos de EASB através do peso corporal, da massa úmida hepática e do conteúdo sérico de albumina. O EASB não altera os parâmetros analisados no presente estudo. Dessa forma, o extrato não foi tóxico nas doses usadas no ensaio.
\end{abstract}

Descritores: Toxicologia; Plantas Medicinais.

\section{Effect of aqueous Scutia buxifolia extract on serum albumin and, rat's body weight}

\begin{abstract}
Scutia buxifolia is a medicinal plant used for the treatment of cardiac diseases but little know about its toxicity on liver. Wistar rats ( $n=32$ ) were divided into 4 groups: control and treated groups with 100, 200 and, $400 \mathrm{mg}$ of lyophilized aqueous extract of S. buxifolia (EASB)/ kg of body weight, daily, during 30 days. The blood of animals was collected on 15th and 30th day of experiment for serum albumin dosage. The blood samples were centrifugated $(3000 \mathrm{rpm})$ for 15 minutes. The present study was planned to explore the hepatotoxic effect of EASB, which was assessed by total body weight, liver weight and, serum albumin. EASB did not alter the parameters analyzed. This way, EASB was not toxic for the liver in the dosages used.
\end{abstract}

Descriptors: Toxicology; Medicinal Plants.

\footnotetext{
${ }^{1}$ Mestre em Ciências Farmacêuticas pela Universidade Federal de Santa Maria (UFSM), Santa Maria, RS, Brasil.

${ }^{2}$ Programa de Pós-Graduação em Ciências Farmacêuticas pela Universidade Federal de Santa Maria (UFSM), Santa Maria, RS, Brasil.

${ }^{3}$ Departamento de Fisiologia e Farmacologia pela Universidade Federal de Santa Maria (UFSM), Santa Maria, RS, Brasil.

${ }^{4}$ Programa de Pós-Graduação em Farmacologia pela Universidade Federal de Santa Maria (UFSM), Santa Maria, RS, Brasil.

${ }^{5}$ Departamento de Tecnologia e Ciência dos Alimentos pela Universidade Federal de Santa Maria (UFSM), Santa Maria, RS, Brasil.
} 


\section{Introdução}

O uso indiscriminado de plantas medicinais e outros produtos naturais podem causar efeitos deletérios à saúde de seus usuários. No Brasil, as plantas medicinais da flora nativa são consumidas com pouca ou nenhuma comprovação de suas propriedades farmacológicas e são propagadas por usuários, comerciantes e pela literatura leiga1.

Comparada com a toxicidade dos medicamentos usados nos tratamentos alopáticos, a toxicidade de plantas medicinais e fitoterápicos pode parecer irrelevante. Esta conclusão é bastante equivocada, pois há poucos estudos pré-clínicos e clínicos realizados com plantas. Devido a isto, a toxicidade de plantas medicinais torna-se um sério problema de saúde pública².

Scutia buxifolia, uma planta encontrada principalmente no sul do Brasil, Argentina e Uruguai, está no cenário das terapias alternativas e, carece de estudos sobre eficácia e segurança ${ }^{3}$.

As cascas da planta são utilizadas na preparação de infusões para o tratamento de doenças cardíacas, além disso, a espécie apresenta propriedade diurética ${ }^{4}$.

No Rio Grande do Sul, adicionam-se as cascas de S. buxifolia ao chimarrão. E, os estudos realizados com a planta limitam-se a investigar sua capacidade antioxidante, metabólitos secundários, ação antifúngica, antibacteriana e atividades biológicas in vitro ${ }^{5-7}$.

Tem-se observado em bancos de dados um número inexpressivo de ensaios sobre toxicidade de plantas medicinais, e os existentes são realizados com plantas da medicina oriental que tem como pilar medicamentos de origem vegetal. Nestes estudos, os protocolos são arquitetados de forma que animais (camundongos, ratos e coelhos) sejam tratados com extratos por intervalos de tempo que podem variar de 1 a 90 dias $^{8-9}$.

Os parâmetros avaliados são principalmente aqueles envolvidos com a função hepática, pois, o fígado é o principal órgão detoxificador do organismo ${ }^{10}$.

As provas mais utilizidas são a atividade sérica das enzimas asparato aminotransferase (AST), alanina aminotransferase (ALT), gama glutamil transferase (GGT) e o conteúdo sérico de albumina. Complementa-se o estudo com análises histopatológicas e histoquímicas. Analisa-se também a ingesta de água e comida e o peso corporal dos animais ${ }^{11}$.

Até o presente momento há poucos estudos sobre efeitos tóxicos de extratos de Scutia buxifolia. Um estudo de Boligon e colaboradores relata os efeitos tóxicos de $S$. buxifolia ao microcrustácio Artemia salina. No entanto, ensaios com A. Salina são preliminares e pouco conclusivos ${ }^{6}$.

Há um relato recente de toxicidade em fígados de ratos tratados com a fração acetato de etila de $S$. buxifolia e, os autores do trabalho descrevem alterações morfológicas em hepatócitos ${ }^{12}$.

A toxicidade aguda em ratos do extrato aquoso de S. Buxifolia foi avaliada através do método preconizado pela Agencia Nacional de Vigilancia Sanitària (ANVISA) no qual testaram 3 doses do extrato. $O$ ensaio não revelou sinais de toxicidade. Dessa forma, os autores acreditam que a dose letal 50 seja maior que a dose de $400 \mathrm{mg} / \mathrm{kg}$ de peso corporal ${ }^{13}$.

O presente estudo objetivou investigar os possíveis efeitos tóxicos do extrato aquoso liofilizado de S. buxifolia (EASB) em ratos através de indicadores de toxicidade como: peso corporal, massa úmida hepática e albumina sérica de ratos em modelo subcrônico de toxicidade.

\section{Materiais e métodos}

\section{1- Planta}

Cascas das raízes de Scutia buxifolia foram coletadas no distrito de Dom Pedrito, Rio Grande do Sul, Brasil

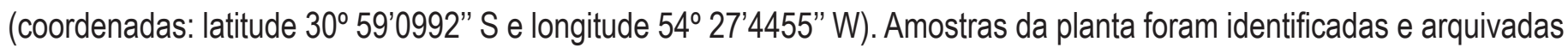
no herbário do Departamento de Biologia da UFSM (número de registro SMBD 10919)

\section{2- Preparação do extrato aquoso liofilizado das cascas de S. buxifolia (EASB)}

As cascas foram secas à temperatura ambiente e trituradas em moinho de facas. Preparou-se um extrato aquoso (infusão), utilizando-se uma proporção de $30 \%$ de cascas em relação à água. A infusão ficou em repouso por 30 minutos à temperatura ambiente. Após ser filtrada, a infusão foi levada a um evaporador rotatório até o máximo esgotamento do solvente (água). Após esse processo esta foi liofilizada, obtendo-se um material seco. Este foi ressuspendido em água nas concentrações indicadas no ensaio biológico. 


\section{3 - Animais}

Neste trabalho foram utilizados 32 ratos Wistar, pesando entre 200 e 250 gramas. Estes permaneceram no biotério setorial do Departamento de Fisiologia e Farmacologia da UFSM, em um ciclo claro/escuro de 12 horas e receberam água e alimento ad libitum.

\section{4- Protocolo experimental}

Para o ensaio da toxicidade subcrônica os ratos foram divididos em quatro grupos:

a) Grupo I (controle): recebeu água destilada (0 mg de EASB / kg de peso corporal) por via intra-gástrica uma vez ao dia, durante 30 dias.

b) Grupo II: recebeu o EASB na dose de $100 \mathrm{mg} / \mathrm{kg}$ por via intra-gástrica uma vez ao dia, durante 30 dias.

c) Grupo III: recebeceu o EASB na dose de $200 \mathrm{mg} / \mathrm{kg}$ por via intra-gástrica uma vez ao dia, durante 30 dias.

d) Grupo IV: recebeu o EASB na dose de 400 mg/kg por via intra-gástrica uma vez ao dia durante 30 dias.

O EASB foi dissolvido em água para obtenção de soluções com as concentrações usadas neste ensaio. O EASB foi administrado por via intragástrica (gavagem), obedecendo a relação de $1 \mathrm{~mL}$ de solução para cada $200 \mathrm{~g}$ de peso corporal.

O protocolo experimental teve apreciação da Comissão de Ética no Uso de Animais (CEUA) e está sob registo de número 091-2011.

\section{5 - Coleta de sangue e preparação da amostras}

0 sangue foi coletado através do plexo retro-orbital e para este procedimento anestesiou-se o olho dos animais com colírio a base de tretracaína e fenilefrina. Este material biológico foi coletado no $15^{\circ}$ e $30^{\circ}$ dias de experimento. Centrifugou-se o sangue a 3000 rpm por 15 minutos e o soro obtido foi usado na dosagem sérica de albumina.

\section{6- Eutanásia}

A eutanásia foi realizada 24 horas após a última administração do extrato ou veículo, através de uma anestesia profunda induzida por tiopental injetado por via intraperitoneal na dose de $100 \mathrm{mg} / \mathrm{kg}$ de peso corporal. Realizou-se uma laparotomia com a finalidade de remover o fígado dos animais.

\section{7- Peso corporal e massa úmida do fígado}

No $30^{\circ}$ dia todos os animais foram pesados. A massa úmida do figado foi determinada em balança analitica e realizada logo após a remoção deste órgão.

\section{8- Determinaçao do conteúdo sérico de albumina}

A albumina sérica foi determinada em analisador automático Cobas Mira® (Roche Diagnostics, Basel, Suiça).

\section{9- Análise estatística}

Após a determinação de todos os parâmetros experimentais, foram calculadas as médias e os erros padrões (E.P.M.) de cada grupo. Na análise estatística, utilizou-se o software GraphPad Prisma, versão 5.0 (GraphPad Software, San Diego, Califórnia, EUA). Realizou-se uma análise de variância de uma via (ANOVA) com o teste complementar de Dunett. Diferenças estatísticas foram consideradas para um $p<0,05$.

\section{Resultados e Discussão}

Produtos de origem vegetal quando consumidos de forma inadequada podem estar relacionados à etiologia de injurias hepáticas, renais e cardíacas. A toxicidade de plantas ocorre quando a ingesta de chás, extratos, tinturas e fitoterápicos é realizada sem indicação clínica e feita de forma indiscriminada ${ }^{14}$.

Scutia buxifolia, vulgarmente conhecida como "coronilha", é uma planta medicinal bastante usada na medicina popular como diurética, cardiotônica e hipotensora ${ }^{15}$. 
Embora, seus efeitos farmacológicos sejam bastante conhecidos, discute-se muito pouco sobre doses tóxicas, terapêuticas e a maneira mais adequada de preparar infusões ${ }^{2}$.

Assim, a escassez destas informações, motivou o estudo de três doses do extrato aquoso liofilizado de S.buxifolia (EASB) em ensaio de toxicidade subcrônica.

AANOVA não revelou alteração no peso corporal dos animais tratados com o extrato, nas diferentes doses testadas em comparaçao ao grupo controle, indicando ausência de efeitos nocivos ao metabolismo dos animais (Figura 1).

Figura 1 - Peso corporal dos animais tratados com EASB. Os dados são expressos em média \pm erro padrão da média.

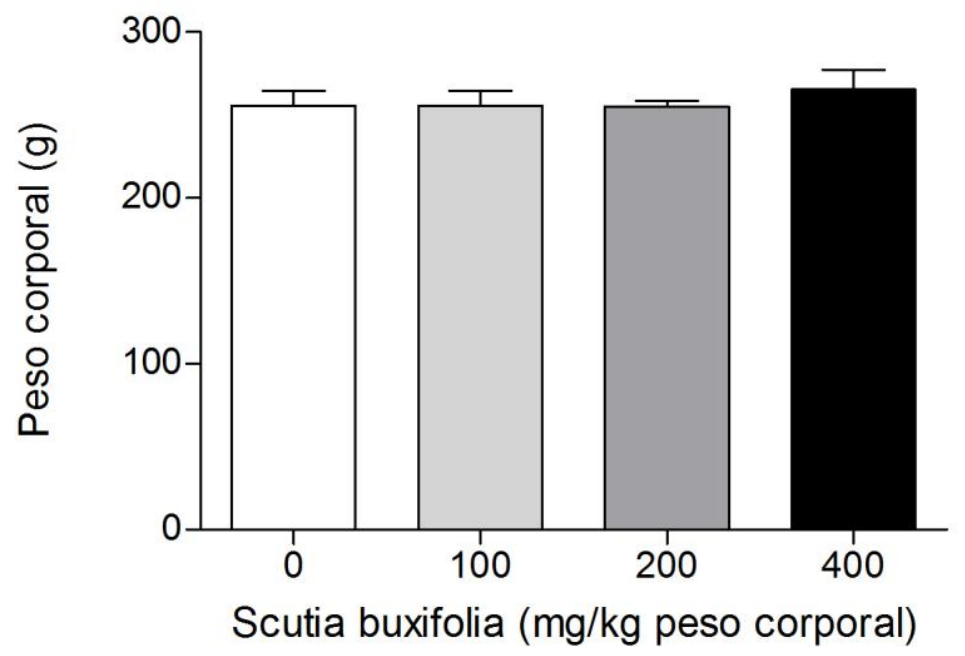

Alterações no metabolismo de animais causadas por plantas tóxicas podem ser atribuídas a interferências na absorção de nutrientes, na fosforilação oxidativa e também, na inibição de processos biossintéticos relacionados às macromoléculas ${ }^{16}$.

Dessa forma, também não foram encontradas mudanças significativas na massa úmida hepática (Figura 2).

Figura 2 - Massa úmida hepática dos ratos tratados com EASB. Os dados são expressos em média \pm erro padrão da média.

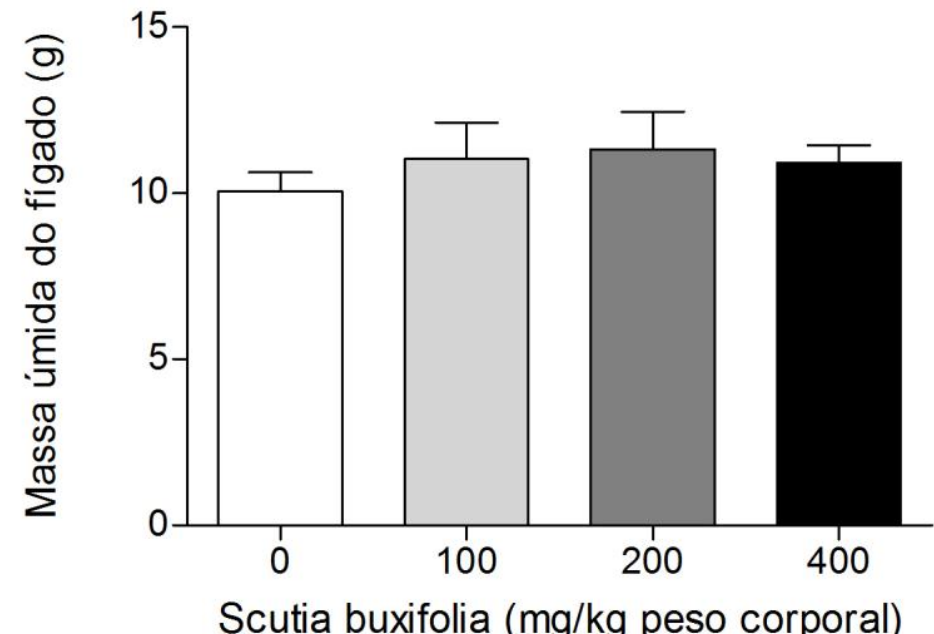

A albumina, uma proteína que aparece em níveis diminuídos em hepatopatias, apresentou escore semelhante nos grupos tratados com EASB em comparação ao do grupo controle (Figura 3) ${ }^{17}$.

Esta proteína é bastante usada na investigação de toxicidade porque se estima que $90 \%$ das proteínas plasmáticas sejam produzidas pelo fígado. A albumina é uma proteína que depende principalmente do aminoácido triptofano para a sua produção, e tem importantes funções, como: manter a pressão oncótica e carrear xenobióticos de maneira inespecífica e pequenas moléculas endógenas. Em hepatopatias, albumina e outras proteínas plasmáticas aparecem no plasma em concentrações diminutas, causando ascite e edema ${ }^{17}$.

Silva e colaboradores analisaram o efeito da fração acetato de etila em camundongos tratados com as doses de 100, 200 e 400 $\mathrm{mg}$ de fração/ $\mathrm{kg}$ de peso corporal. Afração acetato de etila de S. buxifolia provocou injúrias celulares em fígados de camundongos ${ }^{12}$. 
Figura 3 - Conteúdo sérico de albumina em ratos tratados com EASB no $15^{\circ}$ e $30^{\circ}$ dias de tratamento. Os dados são expressos em média \pm erro padrão da média.

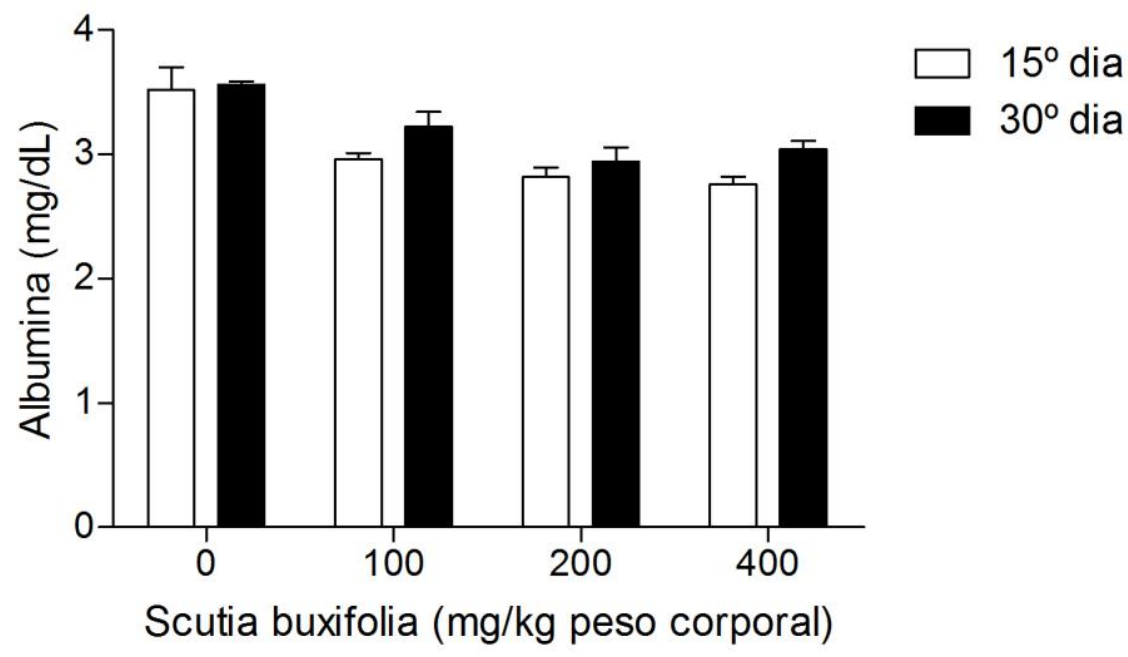

Estas alterações levam ao aumento da atividade da enzima hepática AST. Estudos in vitro e in vivo mostram que alguns compostos antioxidantes de origem vegetal causam danos na membrana celular e aumentam a formação de radicais livres e espécies reativas de oxigênio ${ }^{18}$.

Os autores também detectaram focos de infiltrado inflamatório em hepatócitos de camundongos tratados com a dose mais elevada da fração ${ }^{13}$.

A ingesta de comida e peso corporal dos camundongos pertencentes ao grupo controle são semelhantes aos grupos tratados com a fração, indicando que o metabolismo não foi alterado pelo tratamento com S. buxifolia. Esta informação está de acordo com o nosso achado. Possivelmente, o extrato aquoso tenha menor toxicidade que a fração acetato de etila. Pois, na preparação de frações, mesclam-se solventes como álcool butílico e acetato de etila ao extrato hidroalcoólico com o objetivo de extrair compostos que são mais solúveis em matrizes orgânicas ${ }^{19}$.

Desta forma, concentram-se alguns compostos bioativos. Porém, é sabido que compostos antioxidantes em determinadas concentrações podem apresentar toxicidade ${ }^{20}$.

Em nosso protocolo, foi escolhido o extrato aquoso por este ser mais semelhante às infusões utilizadas na medicina popular. $\mathrm{A}$ análise fitoquímica do EASB revelou o ácido cafeico e a quercetina como compostos majoritários ${ }^{13}$.

A quercetina é um composto da classe dos flavonoides e apresenta ação hepatoprotetora. Este composto tem a propriedade de estimular a decodificação de genes relacionados à síntese de enzimas antioxidantes como a superóxido dismutase e catalase ${ }^{21}$.

Provavelmente, os compostos antioxidantes de EASB juntamente com as defesas antioxidantes endógenas previnem danos hepáticos induzidos por estresse oxidativo.

A análise dos dados revela que o EASB quando administrado por via oral em diferentes concentrações não altera os parâmetros de toxicidade investigados no modelo experimental. Porém, as informações adquiridas necessitam de outras provas como a avaliação de enzimas hepáticas, parâmetros bioquímicos e hematológicos, para a garantia de dados mais conclusivos.

\section{Conflito de interesses}

Os autores não declaram conflito de interesses

\section{Apoio financeiro}

Este estudo foi financiado pelo Fundo de Incentivo à Pesquisa - FIPE - UFSM.

\section{Referências Bibliográficas}

1. Herrera S, Bruguera M. Hepatotoxidad inducida por el uso de hierbas y medicamentos para perderpeso. Gastroenterología y Hepatología. 2008; 31(7): 447: 453.

2. Junior VFV, Pinto AC, Maciel MAM. Plantas medicinais: cura segura?. Química Nova. 2005; 28(23):519-28. 
3. Wasicky R, Wasicky M., \& Joachimovits, R. Erstuntersuchungen na Coronilha- Scutia buxifolia Reissek. Planta Medica, 1964; 12: 13-25.

4. Dickel ML, Rates SMK, Ritter MR. Plants popularly used for losing weight purposes in Porto Alegre, South Brazil. Journal of Ethnopharmacology. 2007; 19: 60-71.

5. Boligon AA, Pereira RP, Feltrin AC, Machado MM, Janovik V, Rocha JB, et al. Antioxidant activities of flavonol derivatives from the leaves and stem bark of Scutia buxifolia Reiss. Bioresource Technology. 2009; 100:6592-598.

6. Boligon AA, Janovik V, Frohlich JK, Spader TB, Froeder AL, Alves SH, et al. Antimicrobial and cytotoxic activities of leaves, twigs and stem bark of Scutia buxifolia Reissek. Natural Product Research. 2012; 26(10):939-44.

7. Morel AF, Maldaner G, Ilha V, Missau F, Silva UF, Dalcol II. Cyclopeptide alkaloids of Scutia buxifolia. Phytochemistry, 2005; 66:2571-76.

8. Santosh N, Mohan K, Royana S, Yamini TB. Hepatotoxicity of tuber of Indian Kudzu (Pueraria tuberosa) in rats. Food and Chemical Toxicology. 2010; 40: 1066-71.

9. Andrade F, Albuquerque CA, Maraschin M, da Silva EL. Safety assessment of yerba mate (llex paraguariensis) dried extract: Results of acute and 90 days subchronic toxicity studies in rats and rabbits. Food and Chemical Toxicology. 2012; 50:318-24.

10. Pouton CW, Haynes JM. Pharmaceutical applications of embryonic stem cells. Advanced Drug Delivery Reviews. 2005: 57(13): 1918-34.

11. Stickel F, Egerer G, Seitz, HK. Hepatotoxicity of botanicals. Public Health Nutrition. 2000; 3(2): 113-24.

12. da Silva AR, Moreira, LR, Brum ES, de Freitas ML, BoligonAA, Athayde ML, Roman, SS. Biochemical and hematological effects of acute and sub-acute administration to ethyl acetate fraction from the stem bark Scutia buxifolia Reissek in mice. Journal of Ethnopharmacology. 2014, 153(3): 908-916.

13. Freitas RB, Araldi ICC, Boligon AA, Brum TF, Rovani BT, Piana M, Zadra M, Athayde ML, Bauermann FL. Phytochemical analysis and toxicity investigation of stem bark of Scutia buxifolia Reissek. Natural Product Research. 2013; 27(18):1620-4.

14. Zhou S, Koh HL, Gao Y, Gong ZY, Lee EJ. Herbal bioactivation: the good, the bad and the ugly. Life Sciences 2004; 74(8): $935-68$. 15. Silva RC, Crestani S, Souza P, Boligon AA, Athayde ML, Santos AR, Marques MC, Kassuya CA, Silva JES. Endothelium-dependent and independent vasorelaxation induced by an $n$-butanolic fraction of bark of Scutia buxifolia Reiss (Rhamanaceae). Journal of Ethnopharmacology. 2012; 141(3):997-04.

16. Rebecca MA, Ishii-Iwamotob EM, Grespana R, Cumana RKN, Melloc JCP, Bersani-Amado, CA. Toxicological studies on Stryphnodendron adstringens. Journal of Ethnopharmacology. 2002; 83:101-04.

17. Corns CM. Herbal remedies and clinical biochemistry. Annal of Clinical Biochemistry. 2003; 40:489-07.

18. Galati, GLA, Sultan, AM, O'brien, PJ. Cellular and in vivo hepatotoxicitycaused by green tea phenolic acids and catechins. Free Radical Biology and Medicine. 2006; 40, 570-580.

19. SIMÕES, C. et al. Farmacognosia: da planta ao medicamento. $2^{a}$ edição Porto Alegre/Florianopolis: Editora da UFRGS/Editora da UFSC, 2000.

20. Halliwell B, Gutteridge JC. Free Radicals in Biology and Medicine. Oxford University Press: NewYork, 2007.

21. Barcelos, GRM et al. Quercetin protects human-derived liver cells against mercury-induced DNA-damage and alterations of the redox status. Mutation Research. 2011; 726: 109-115. 


\section{Robson Borba de Freitas}

Endereço para correspondência - Av Roraima, $n^{\circ}$ 1000, prédio 21, sala 5229, CEP: 97105-900, Cidade: Santa Maria, RS, Brasil.

E-mail: robsonborbaf@gmail.com

Lattes: http://lattes.cnpq.br/9284352038719663

Roberta da Silva Jesus - robertasj@hotmail.com

Isabel Cristina da Costa Araldi - araldi.isabel@gmail.com

Bruno Tomazele Rovan - brunorovani@gmail.com

Thiele Faccim de Brum - thi_chaim@yahoo.com.br

Mariana Piana - marianarpiana@gmail.com

Aline Augusti Boligon - alineboligon@hotmail.com

Glauce Regina Pigatto - glaucepigatto@hotmail.com

Gilberti Helena Hübscher Lopes - gilberti@gilbertinutri.com.br

Margareth Linde Athayde - margathayde@gmail.com

Liliane de Freitas Bauermann - Ifgbauermann@gmail.com

\section{Enviado em 06 de maio de 2014.} Aceito em 19 de março de 2015. 
